\title{
Combining genetic and epigenetic parameters of the serotonin transporter gene in obsessive-compulsive disorder
}

Grünblatt, Edna ; Marinova, Zoya ; Roth, Alexander ; Gardini, Elena ; Ball, Juliane ; Geissler, Julia ; Wojdacz, Tomasz K ; Romanos, Marcel ; Walitza, Susanne

DOI: https://doi.org/10.1016/j.jpsychires.2017.10.010

Posted at the Zurich Open Repository and Archive, University of Zurich ZORA URL: https://doi.org/10.5167/uzh-141713

Journal Article

Accepted Version

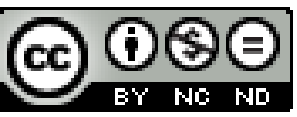

The following work is licensed under a Creative Commons: Attribution-NonCommercial-NoDerivatives 4.0 International (CC BY-NC-ND 4.0) License.

Originally published at:

Grünblatt, Edna; Marinova, Zoya; Roth, Alexander; Gardini, Elena; Ball, Juliane; Geissler, Julia; Wojdacz, Tomasz K; Romanos, Marcel; Walitza, Susanne (2018). Combining genetic and epigenetic parameters of the serotonin transporter gene in obsessive-compulsive disorder. Journal of Psychiatric Research, 96:209-217.

DOI: https://doi.org/10.1016/j.jpsychires.2017.10.010 


\section{Accepted Manuscript}

Combining genetic and epigenetic parameters of the serotonin transporter gene in obsessive-compulsive disorder

Edna Grünblatt, Zoya Marinova, Alexander Roth, Elena Gardini, Juliane Ball, Julia Geissler, Tomasz K. Wojdacz, Marcel Romanos, Susanne Walitza

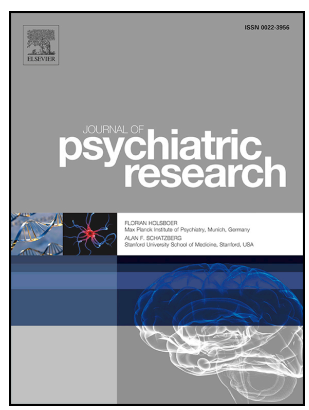

PII: S0022-3956(17)30318-7

DOI: 10.1016/j.jpsychires.2017.10.010

Reference: $\quad$ PIAT 3233

To appear in: Journal of Psychiatric Research

Received Date: 16 March 2017

Revised Date: 13 October 2017

Accepted Date: 13 October 2017

Please cite this article as: Grünblatt E, Marinova Z, Roth A, Gardini E, Ball J, Geissler J, Wojdacz TK, Romanos M, Walitza S, Combining genetic and epigenetic parameters of the serotonin transporter gene in obsessive-compulsive disorder, Journal of Psychiatric Research (2017), doi: 10.1016/ j.jpsychires.2017.10.010.

This is a PDF file of an unedited manuscript that has been accepted for publication. As a service to our customers we are providing this early version of the manuscript. The manuscript will undergo copyediting, typesetting, and review of the resulting proof before it is published in its final form. Please note that during the production process errors may be discovered which could affect the content, and all legal disclaimers that apply to the journal pertain. 
Combining genetic and epigenetic parameters of the serotonin transporter gene in obsessive-compulsive disorder

Edna Grünblatt ${ }^{1,2,3,{ }^{*}}{ }^{凶}$, Prof. PhD, Zoya Marinova ${ }^{1, *}, \mathrm{MD} / \mathrm{PhD}$, Alexander Roth ${ }^{1}$, Dr. sc. hum., Elena

Gardini $^{1}$, MSc., Juliane Ball ${ }^{1}$, Dr. rer. nat., Julia Geissler ${ }^{4}$, Dr. rer. nat., Tomasz K. Wojdacz ${ }^{5,6}$ PhD, Marcel Romanos ${ }^{4}$, Prof. Dr. med., Susanne Walitza ${ }^{1,2,3,}$ Prof. Dr. med. Dipl.-Psych.

Affiliations:

1) Department of Child and Adolescent Psychiatry and Psychotherapy, Psychiatric Hospital, University of Zurich, Zurich, Switzerland

2) Neuroscience Center Zurich, University of Zurich and ETH Zurich, Zurich, Switzerland

3) Zurich Center for Integrative Human Physiology, University of Zurich, Switzerland

4) Center of Mental Health, Department of Child and Adolescent Psychiatry, Psychosomatics and Psychotherapy, University Hospital of Würzburg, Würzburg, Germany

5) Department of Biomedicine, Aarhus University, Wilhelm Meyers Allé 3, Build. 1230, DK-8000 Aarhus, Denmark

6) Aarhus Institute of Advanced Studies, Høegh-Guldbergs Gade 6B, DK-8000 Aarhus C, Denmark

* Both first authors have contributed equally;

Abstract: 261 words Whole manuscript: 4460 words

References: 77 Tables: 3 Figures: 2 Supplementary materials: 9 (methods=1; results=1;

Figures $=2$; Tables $=5$ )

Running title: Serotonin transporter DNA methylation in OCD

\section{Correspondence to}

${ }^{\bowtie}$ Prof. Dr. Edna Grünblatt; Department of Child and Adolescent Psychiatry and

Psychotherapy, Psychiatric Hospital, University of Zurich, Wagistrasse 12, 8952 Schlieren,

Switzerland; Tel: +41-43-556-4039; E-mail: edna.gruenblatt@kjpd.uzh.ch 


\section{Abstract}

While genetic variants have been reported to be associated with obsessive-compulsive disorder (OCD), the small effect sizes suggest that epigenetic mechanisms such as DNA methylation may also be relevant. The serotonin transporter (SLC6A4) gene has been extensively investigated in relation to $\mathrm{OCD}$, since serotonin reuptake inhibitors are the pharmacological treatment of choice for the disorder. The current study set three questions: Firstly, whether the high expressing loci of the SLC6A4 polymorphisms, 5HTTLPR+rs25531, rs25532 and rs16965628 are associated with family-based (n=164 trios) and case-control OCD ( $\mathrm{n}=186,152$, respectively). This was also examined by a meta-analysis. Secondly, whether DNA methylation and RNA levels of the SLC6A4 differ in saliva and blood of a subset of samples from pediatric and adult OCD patients and matched controls. And lastly, whether morning awakening cortisol levels correlate with the above. A metaanalysis confirmed the association of the $\mathrm{L}_{\mathrm{A}}$-allele with $\mathrm{OCD}(\mathrm{OR}=1.21, \mathrm{p}=0.00018)$, maintaining significance in the early-onset $\mathrm{OCD}$ subgroup $(\mathrm{OR}=1.21, \mathrm{p}=0.022)$. There was no association between rs25532 or rs 16965628 and OCD. Our preliminary data showed that SLC6A4 DNA methylation levels in an amplicon located at the beginning of the first intron were significantly higher in the saliva of pediatric OCD patients compared to controls and adult patients with OCD, but no alterations in RNA levels or in polymorphism interactions were observed. Morning awakening salivary cortisol levels positively correlated with methylation levels, and negatively correlated with RNA levels. This study further supports the involvement of the SLC6A4 gene in OCD through both genetic and epigenetic mechanisms. This finding needs to be explored further in an independent large sample. 
Keywords: obsessive-compulsive disorder; serotonin transporter (SLC6A4); DNA

methylation; rs25531; rs25332; rs16965628; 5-HTTLPR; biomarker; RNA; gene expression; cortisol 


\section{Introduction}

Obsessive-compulsive disorder (OCD) is a neuropsychiatric disorder, presenting with distressing, recurrent, persistent thoughts and compulsive, repetitive behaviors (American Psychiatric Association, 2013). The disease is present in both adults and children, affecting 0.1 to $2.3 \%$ of the population (Ruscio et al., 2010; Wittchen et al., 2011). Despite strong heritability estimates from twin and family studies ranging between 40 and $80 \%$, increasing proportionally to the degree of genetic relatedness (Mataix-Cols et al., 2013; Pauls et al., 2014; van Grootheest et al., 2005), two recent genome-wide association studies (Mattheisen et al., 2014; Stewart et al., 2013) failed to detect genome-wide significances for single nucleotide polymorphisms (SNPs) in OCD. Indeed, it is postulated that both genetic and environmental factors may play an important role in the risk for OCD (Mataix-Cols et al., 2013).

The serotonergic system has been widely studied in relation to OCD, and selective serotonin reuptake inhibitors are the drug of choice for OCD treatment (Murphy et al., 2013). One of the genes most consistently associated with OCD is the serotonin transporter (SLC6A4) (Bloch et al., 2008; Dickel et al., 2007; Taylor, 2013; 2016). A polymorphism in the serotonin transporter-linked polymorphic region (5-HTTLPR) with a high-expressing L allele and a low-expressing $\mathrm{S}$ allele has been associated with $\mathrm{OCD}$, with the $\mathrm{L}$ allele being the risk allele (Baca-Garcia et al., 2005; Bengel et al., 1999; McDougle et al., 1998). Nevertheless, several studies have failed to replicate this finding, partly because of sample size, but probably also due to the high variability in study design or patient samples (Atmaca et al., 2011; Billett et al., 1997; Camarena et al., 2001; Cengiz et al., 2015; Chabane et al., 2004; Denys et al., 2006; Di Bella et al., 2002; Dickel et al., 2007; Frisch et al., 2000; Grados et al., 2007; Kim et al., 2005; Kinnear et al., 2000; Liu et al., 2011; Meira-Lima et al., 2004; Saiz et al., 2008; Walitza et al., 2004). Nonetheless, a meta-analysis demonstrated a significant association, albeit with a rather small effect size (Bloch et al., 2008; Dickel et al., 
2007; Taylor, 2013; 2016). In $2006 \mathrm{Hu}$ et al. described the presence of an additional SNP rs25531, within the 5-HTTLPR repetitive region (Hu et al., 2006). The $\mathrm{G}$ allele of rs25531 was found to convert the $\mathrm{L}$ allele into a functionally $\mathrm{S}$ allele (Hu et al., 2006). This allows the division of the 5-HTTLPR modulated by rs 25531 into a triallelic polymorphism: $\mathrm{L}_{\mathrm{A}}$, which is high-expressing and $\mathrm{L}_{\mathrm{G}}$ and $\mathrm{S}$ (from here on referred to as $\mathrm{S}$ ), which are low-expressing. The association of the triallelic 5-HTTLPR polymorphism with OCD risk has since been investigated in both adult and early-onset samples (Honda et al., 2017; Hu et al., 2006; Kenezloi et al., 2010; Moya et al., 2013; Rocha et al., 2009; Tibrewal et al., 2010; Tükel et al., 2016; Voyiaziakis et al., 2011; Walitza et al., 2014; Wendland et al., 2007), in which a significant association of the $\mathrm{L}_{\mathrm{A}}$ allele has been confirmed by our group in a small metaanalysis of OCD patients (Walitza et al., 2014). In addition, modulation of 5-HTTLPR functionality by the non-coding SLC6A4 polymorphisms rs25532 and rs 16965628 has been demonstrated (Martin et al., 2007; Wendland et al., 2008). A haplotype containing the higherexpressing allele at all three loci: the 5-HTTLPR triallelic polymorphism $\left(\mathrm{L}_{\mathrm{A}}\right), \mathrm{rs} 25532(\mathrm{C})$ and rs16965628 (C) was found to be associated with higher OCD risk (Wendland et al., 2008). Nevertheless, the following studies could not fully replicate this finding (Cengiz et al., 2015; Kenezloi et al., 2010; Moya et al., 2013).

Environmental factors, e.g. model learning, stress (e.g. stressful life events), trauma, are known to be important risk factors in the development of OCD (Faravelli et al., 2012; Gothelf et al., 2004; Morina et al., 2016) and are also known to modify gene transcription and expression. Furthermore, it was reported that perceived stress and basal cortisol levels were significantly higher in OCD patients than in controls (Morgado et al., 2013). Therefore, epigenetics is regarded as an important interface between environmental alterations causing changes in gene expression. Such epigenetic alterations regulate the accessibility for transcription factors and influence gene expression (Jaenisch \& Bird, 2003). Epigenetic mechanisms may also play a role in the pathophysiology of OCD, as has already been 
demonstrated in two preliminary genome-wide methylome analyses conducted in patients with OCD (Nissen et al., 2016; Yue et al., 2016). Nissen et al. (2016) reported in females with OCD differential methylation for GABBRlin blood samples at birth as well as for $M O G$ and $B D N F$ in blood samples at the time of diagnosis. Yue et al. (2016) found 8,417 probes corresponding to 2,190 genes being differentially methylated between OCD and healthy controls. Pathway analyses revealed that regulation of actin cytoskeleton, cell adhesion molecules, actin binding and transcription regulator activity pathways were involved. DNA methylation is one type of epigenetic modification that may affect gene transcription and consequently function. DNA methylation alterations of SLC6A4 in several psychiatric diseases as well as in behavioral adversities have been detected (Provenzi et al., 2016; Sugawara et al., 2013). However, the role of SLC6A4 epigenetic modifications in OCD is not yet clear. The focus of the present DNA methylation study will be on the SLC6A4 gene due to the repeatedly confirmed involvement of the serotonergic system in OCD and the fact that the serotonin transporter is the pathogenetic target of the first-line medications used for OCD treatment.

In the current study we set out to re-investigate the association of the three high expressing loci of the SLC6A4 polymorphisms 5-HTTLPR+rs25531, rs25532 and rs 16965628 in early-onset family-based trios and case-control OCD, including a new meta-analysis covering current publications. Moreover, to investigate environmental effects on the genome, we compared DNA methylation levels of an amplicon located at the beginning of the first intron of SLC6A4 in blood and saliva samples of a subset of pediatric and adult OCD patients and demographically-matched controls as well as their peripheral whole blood gene expression profile. Lastly, we looked at the correlations between these parameters and morning awakening cortisol levels.

\section{Materials and Methods}


For the case-control study, 186 early-onset pediatric OCD patients and 164 childparent trios (465 individuals) were recruited at the Departments of Child and Adolescent Psychiatry of the Universities of Würzburg, Zurich ( $n=145$ patients from Würzburg \& Zurich), Marburg, Aachen, and Freiburg. One hundred and fifty-two healthy controls were recruited at the Departments of Child and Adolescent Psychiatry of the Universies of Würzburg and Zurich. The ethnicity of all participants was German or Swiss. Informed written consent was obtained in all cases from the participants or their parents. The study was approved by the ethical commissions of all involved universities in accordance with the latest version of the Declaration of Helsinki, including an ethical permission granted by the Ethic Committees from Aachen, Würzburg, Marburg, Freiburg, and the Cantonal Ethic Commission of Zürich (Ref. Nr. 39/97, 140/3 and EK: KEK-ZH-Nr. 2010-0340/3). Demographic characteristics of family and case-control study groups are summarized in Table 1 (for detailed inclusion and exclusion criteria see Supplementary methods).

A sub-sample of participants was used for the SLC6A4 methylation (from saliva) and the gene expression (whole blood) and salivary cortisol levels consisting of four groups: pediatric OCD, adult OCD and their matching controls (part of a neuroimaging study described elsewhere (Hauser et al., 2017); for details see Supplementary methods and Table S1). Blood DNA methylation analysis was conducted using a collection of samples from an additional group of independent pediatric OCD patients.

In line with the first aim of the present study, this was an extension and re-evaluation of a previously published significant association analysis with a transmission disequilibrium test (TDT) and meta-analysis of the 5-HTTLPR + rs25531 (triallelic) in OCD (Walitza et al., 2014). The current study enlarged the family TDT sample (61 new cases and parents), added a case-control analysis and two additional SNPs (rs25532 and rs16965628), as well as a newly run meta-analysis with additional newly published data. 
The Oragene DNA collection kit was used for DNA isolation from saliva, following the manufacturer's protocol (DNA Genotek; Canada). Following a previously described protocol for DNA isolation (Grünblatt et al., 2005), $2 \mathrm{ml}$ of EDTA blood and proteinase $\mathrm{K}$ were used for DNA isolation from whole blood samples. DNA concentration, A260/A280 and A260/A230 ratios were measured with a NanoVue Plus spectrophotometer (GE Healthcare, Switzerland).

\section{Genotyping}

The restriction fragment length polymorphism method was used for the 5-HTTLPR triallelic (combined with the rs25531) polymorphism analysis (for detailed methods see Supplementary methods). The $\mathrm{L}_{\mathrm{A}}$ and $\mathrm{L}_{\mathrm{G}}$ alleles were distinguished based on the analysis of amplicon and restriction fragment sizes as previously described (Nyffeler et al., 2014; Wendland et al., 2006). Alleles were collapsed according to high functionality of La (labelled as L) versus low functionality of S or $\mathrm{Lg}$ (labelled as $\mathrm{S}$ ).

For the rs16965628 and rs25532 SNPs, genotyping was performed using TaqMan® SNP Genotyping Assays (Life Technologies, Switzerland; for details see Supplementary methods).

\section{Meta-analysis}

We conducted a systematic review using the preferred reporting items for systematic reviews and meta-analysis criteria (PRISMA) (Moher et al., 2009). Articles were searched to include studies that described association studies for SLC6A4 (HTTLPR+rs25531, rs16965628 \& rs25532) in OCD (for details see Supplementary methods). The final search was undertaken on February $2^{\text {nd }} 2017$. A meta-analysis was conducted with the extracted data and the current study data using the MIX 2.0 Pro v.2.0.1.4 (BiostatXL, 2011. http://www.meta-analysis-made-easy.com). Variability due to between-study heterogeneity was estimated by $\mathrm{I}^{2}$ and funnel plots, publication bias using Begg's and Egger's regression 
test (Begg \& Mazumdar, 1994; Egger et al., 1997), and the quality of the studies was assessed based on traditional epidemiological considerations (Supplementary Figure S1 and Table S2). Bisulfite modification

For the second study aim, the Universal Methylated Human DNA Standard (Zymo Research, CA, USA) was used as methylated human DNA standard. The unmethylated human control DNA (Qiagen) was used as unmethylated human DNA standard. $500 \mathrm{ng}$ of genomic DNA from each sample (saliva or blood) and from the methylated/ unmethylated DNA controls was bisulfite converted with the EZ DNA Methylation-Gold Kit (Zymo Research), following the manufacturer's instructions and using a final elution volume of $55 \mu$ PCR grade water.

\section{Methylation sensitive-high resolution melting (MS-HRM) analysis and data quantification}

Astandard curve was constructed using bisulfite-converted artificially methylated (Zymo Research) and unmethylated DNA (Qiagen) in different dilutions to acquire 0\%, 0,1\%, $0.5 \%, 1 \%, 5 \%$, and $100 \%$ standards. The following primers were used for MS-HRM: SLC6A4 forward primer - CGAGGAGGCGAGGAGGTGT; SLC6A4 reverse primer CGTTCCTCGTCTCCCACTCTAA (for chromosomal location and CpG sites see Suppl. Figure S2). Methylation sensitive-high resolution melting experiments were carried out with the LightCycler 480 High Resolution Melting Master mix (Roche Diagnostics Schweiz AG, Switzerland), $250 \mathrm{nM}$ primers and $1.5 \mu \mathrm{l}$ of the bisulfite converted DNA, $2.5 \mathrm{mM} \mathrm{Mg}$ and water to complete the required volume. PCR and preliminary analysis of the data was conducted on the CFX96 real-time Thermal Cycler (Bio-Rad) and the Precision MeltAnalysis Software v1.2 (BioRad). For quantification of the data, a polyfit interpolating model in Matlab $^{\circledR}$ v.8.6 (Math Works) was used, according to a previously published protocol and algorithm obtained by the authors (Migheli et al., 2013).

Total RNA extraction and quantitative real-time $R T-P C R$ 
Whole blood was collected with the PAXgene ${ }^{\mathrm{TM}}$ Blood RNA system (Becton Dickinson GmbH, Heidelberg, Germany), and total RNA was extracted using the PAXgene $e^{\mathrm{TM}}$ Blood RNA Kit 50 (PreAnalytiX, Qiagen and BD, Germany). Quantitative real-time RT-PCR was conducted for SLC6A4 (QT00058380) gene and six additional reference genes (ACTBQT00095431, GAPDH- QT00079247, ALAS1- QT00073122, RPL13A- QT00089915, PPIAQT00052311, and 18S ribosomal RNA- QT00199367) as described previously (Grünblatt et al., 2009) (for further details see Supplementary methods). Gene expression and normalization analysis with the most stable reference genes was conducted using the qBasePLUS v.2.3 (Biogazelle) (Vandesompele et al., 2002).

Salivary free cortisol levels

For the third aim, investigating correlations between the aforementioned parameters and cortisol levels, we analyzed a sub-set of the salivary cortisol levels at morning wake-up time. Active free cortisol in saliva was measured in samples collected at baseline (directly after wake-up time; expected cortisol values 1-11-3 ng/ml 5-95\% percentile). Cortisol levels were measured with cortisol free in saliva ELISA (DES6611, Demeditec Diagnostics GmbH, Germany) following the manufacturer's protocol (for further details see Supplementary methods).

\section{Statistical analysis}

All association studies were run on the PLINK v1.7 (URL: http://pngu.mgh.harvard.edu/purcell/plink/ (Purcell et al., 2007)). Each study group (casecontrol study) was tested for Hardy-Weinberg equilibrium (HWE) (Suppl. Table S3). For the case-control association study, the Fisher's Exact Test was conducted and significance was set at $\mathrm{p}<0.017$ for multiple testing. For the family association study, Mendel errors test (none were found) followed by the transmission disequilibrium test (TDT) was conducted as well as a parent-of-origin analysis. 
Statistical analysis was carried out with SPSS v23 (IBM) and SAS 9.4. To test the normality of the DNA methylation levels distribution, the Komogorov-Smirnov and ShapiroWilk tests were used. To ensure consistency, non-parametric assessments were carried out throughout the manuscript. The Mann-Whitney test was used for comparisons between two groups and the Kruskal-Wallis $\mathrm{H}$ test for comparisons between more than two groups. To control for possible confounding factors for SLC6A4 methylation levels (i.e. gender, age, groups: pediatric OCD and their respective controls, and SSRI medication), an ANCOVA was conducted. This analysis was only conducted for the pediatric OCD group as the group size was too small in the adults to concurrently test for multiple confounders. A model containing only main effects was used. Assumptions for the ANCOVA were tested by visual inspection of standardized residuals versus predicted plot in order to rule out heteroscedasticity. Observations with standardized residuals higher than 3 or below -3 were excluded from the analysis. This led to the exclusion of one participant. Spearman's rank test was used for continuous variables correlations. Statistical corrections for multiple comparisons were not conducted due to the explorative nature of this study in which the objective was the generation of a new hypothesis for epigenetics in OCD.

\section{Results}

SLC6A4 promoter polymorphisms association in early-onset pediatric OCD

In the case-control association study there were no significant associations between 5HTTLPR+rs25531, rs16965628 and rs25532 and early-onset pediatric OCD, shown in Table 2. Similarly, in the family-based TDT association study we did not observe a significant transmission of the SLC6A4 polymorphism alleles in our OCD-affected child-parent trios (Table 3). However, in rs25532 we observed a nominally significant p-value (0.0455) for paternal under-transmission of the minor T-allele (Table 3). Haplotype association analysis (see detailed results in supplementary results Table S6 \& S7), resulted in a nominal significant 
haplotype $\mathrm{H} 4\left(\mathrm{~L}_{\mathrm{A}} ; \mathrm{T}\right)$ of the 5-HTTLPR+rs25531 and rs25532 $(\mathrm{p}=0.031)$, while no significant association was found for the three-locus haplotype and early-onset OCD.

\section{Meta-analysis for SLC6A4 promoter polymorphism in OCD}

In order to evaluate the association of the studied SLC6A4 promoter polymorphism with OCD, we included the current data of the case-control and TDT study in a meta-analysis of all published studies (Fig. 1). For 5-HTTLPR+rs25531 we could include three new publications of adult OCD from Turkey (Tükel et al., 2016), pediatric OCD from Hungary (Kenezloi et al., 2010), and adult OCD Brazilian-Caucasian (Rocha et al., 2009), together with our new case-control and the enlarged TDT sample of the previously published study (Walitza et al., 2014). We excluded a study reporting genetic association between 5HTTLPR+rs25531 and rs25532 of adult Tourette patients comorbid with OCD (Moya et al., 2013), since DSM-5 differentiates between Tourette and OCD. A study of adult OCD and 5HTTLPR+rs25531 by Honda et al. (Honda et al., 2017) was also excluded, as it deviated from all other studies causing an increase in heterogeneity $\left(\mathrm{I}^{2}\right)$. It also demonstrated low quality scores and was the only Asian ethnicity (see supplementary Table S2). We observed a significant meta-analysis p-value of 0.00018 for association of the $\mathrm{L}_{\mathrm{A}}$ allele with $\mathrm{OCD}$ (total $\mathrm{n}=5026$, cases $\mathrm{n}=1972, \mathrm{OR}=1.2104,95 \%$ confidence interval $(\mathrm{CI}) 1.095-1.338$, Fig. $1 \mathrm{~A})$. We further stratified the meta-analysis by age of onset, as this was thought to be an important variable in association studies (Mattina \& Steiner, 2016), only running the analysis for earlyonset pediatric OCD publications. This analysis demonstrated a significant association between the $L_{A}$ allele with early-onset $O C D$ (total $n=2944$, cases $n=1086, O R=1.207,95 \%$ CI 1.027-1.418, p-value $=0.022$, Fig. 1B). For rs16965628 (3 studies (Cengiz et al., 2015; Kenezloi et al., 2010; Wendland et al., 2008) + current TDT and case-control) and rs25532 (2 studies (Kenezloi et al., 2010; Wendland et al., 2008) + current TDT and case-control), there was no significant meta-analysis association between $\mathrm{OCD}$ and the $\mathrm{C}$ allele or $\mathrm{T}$ allele, respectively (rs16965628: total $n=2251$, cases $n=827$, OR $=0.846,95 \%$ CI $0.527-1.357, p-$ 
value $=0.487$, Fig. $1 C ;$ rs $25532:$ total $n=2075$, cases $n=747$, OR $=0.798,95 \%$ CI $0.624-$ 1.02, p-value $=0.072$, Fig. 1D). Moreover, we observed a significantly high heterogeneity for rs16965628 (supplementary Table S2).

SLC6A4 DNA methylation and gene-expression of pediatric- and adult-OCD patients and healthy controls

The subset population in which DNA and RNA was collected for SLC6A4 DNA methylation and gene expression levels consisted of pediatric OCD patients with age and gender matched controls and adult OCD patients with age and gender matched adult controls (Suppl. Table S1). The gender ratio, age, age of onset and (C)Y-BOCS scores (for the OCD groups) were significantly different between the pediatric and adult groups (more female $\mathrm{F} / \mathrm{M}=10 / 8$ adult vs. $12 / 32$ saliva pediatric, 20 years older, higher age of onset $15.98 \pm 1.76$ years in adults vs. $9.94 \pm 0.47$ years in saliva pediatric and lower Y-BOCS in adult group $16.4 \pm 2.56$ vs. CY-BOCS $23.34 \pm 1.0$ in saliva pediatric OCD).

SLC6A4 methylation levels were significantly higher (1.6 $\mathrm{x}$ of pediatric control) in early-onset pediatric OCD patients compared to healthy pediatric controls as demonstrated by a Mann-Whitney test $(p<0.05)$ (Fig. 2A). Furthermore, methylation levels were significantly lower in adult OCD compared both to adult controls (36\% of adult controls) and pediatric OCD samples ( $21 \%$ of pediatric OCD; Fig. 2A). To investigate whether both saliva and blood tissue served as a source of DNA methylation biomarker, we compared methylation levels between two independent pediatric OCD groups in which DNA was isolated from either saliva or blood. The SLC6A4 DNA methylation levels were significantly lower in the blood sample compared to the saliva group (Mann-Whitney test, $\mathrm{p}<0.05$ ). Furthermore, there was a negative correlation between SLC6A4 DNA methylation levels in the saliva of pediatric OCD patients and OCD symptom severity as measured by the CY-BOCS $\left(\mathrm{r}_{\mathrm{s}}(42)=-0.380, \mathrm{p}=\right.$ $0.013)$ as well as with the age of patients at the time of assessment $\left(r_{s}(42)=-0.358, p=0.02\right)$ (Suppl. Table S4). There were no significant correlations between the SLC6A4 methylation 
levels in the blood of pediatric OCD patients and any of the parameters. Furthermore, there were no significant correlations between SLC6A4 methylation levels in the saliva of pediatric control participants and any of the parameters (Suppl. Table S4). Methylation levels of SLC6A4 were significantly higher in pediatric female controls compared to males (m (32): $0.058 \pm 0.062 \%$ f (20): $0.099 \pm 0.066 \%, \mathrm{p}<0.05)$. No methylation differences were observed between males and females in the saliva or blood of pediatric OCD patients (supplementary Table S1). Since gender, age, and SSRI medication may play a role in SLC6A4 methylation levels, these parameters were included as confounders in an ANCOVA analysis. This analysis demonstrated significantly higher methylation levels in children and adolescents with OCD compared to healthy controls, with age and gender as confounders, while SSRI treatment resulted in a non-significant effect on $S L C 6 A 4$ methylation levels $(F(1,83)=0.03, p=0.8558)$. When this last parameter was omitted from the ANCOVA analysis, age $(F(1,84)=5.17$, $\mathrm{p}=0.025$; increasing age within 1 year causes decrease in methylation of 0.0059 ), gender $(\mathrm{F}(1,84)=10.51, \mathrm{p}=0.0017$; females gender increase methylation of 0.051$)$, and group $(\mathrm{F}(1,84)=5.41, \mathrm{p}=0.0224$; pediatric $\mathrm{OCD}$ group increase methylation of 0.035$)$ had a significant effect on the methylation levels.

There were no significant alterations in SLC6A4 gene expression levels between the four groups (Fig. 2B). SLC6A4 mRNA levels did not correlate with salivary SLC6A4 DNA methylation levels (Suppl. Table S5).

SLC6A4 DNA methylation, mRNA and salivary cortisol levels of pediatric-and adult-OCD patients and healthy controls

Morning awakening salivary cortisol measurements were taken in the subsetpopulation to allow for the measurement of concomitantly salivary SLC6A4 DNA methylation and blood gene expression (total $n=61$; see Suppl. Table S1). Morning cortisol levels in both pediatric and adult OCD patients were significantly lower than in age matched controls (Suppl. Table S1). Since cortisol levels are suggested to influence DNA methylation, a 
correlation analysis was conducted. A correlation analysis of the complete sample of controls and OCD demonstrated a positive correlation between SLC6A4 DNA methylation levels and morning salivary cortisol levels $\left(\mathrm{r}_{\mathrm{s}}(41)=0.323, \mathrm{p}=0.039\right)($ Suppl. Table S5).

\section{Discussion}

The current study was able to confirm and strengthen the association between the refined 5-HTTLPR+rs25531 polymorphism and OCD as well as demonstrating its association in the stratified analysis of early-onset pediatric OCD. However, we were not able to find an association between the two other SNPs on the SLC6A4 gene and OCD, even after a metaanalysis. Since $\mathrm{Hu}$ and colleagues (Hu et al., 2006) described the refined 5-HTTLPR polymorphism, several meta-analyses have been conducted, with some finding an association with OCD (Dickel et al., 2007; Taylor, 2013; 2016; Walitza et al., 2014) whilst others have not (Bloch et al., 2008; Lin, 2007; Mak et al., 2015). These inconsistencies are most likely to have arisen from some studies only analyzing the 5-HTTLPR polymorphism without the modification of the rs 25531 or in combination with the refined 5-HTTLPR+rs 25531 polymorphism. Indeed, as discussed previously, age of onset and gender seem to play a role in genetic association in OCD (Mattina et al., 2016), as our stratified analysis of 5HTTLPR+rs25531 demonstrated a significant association with early-onset OCD. For the two additional SNPs, since heterogeneity was rather large, a larger and more homogenous sample would be required to prove or reject the association.

After finding that the 5-HTTLPR+rs25531 played a role in the risk of OCD, we tested whether SLC6A4 DNA methylation levels were altered in OCD patients. Our preliminary data suggested increased DNA methylation levels of the SLC6A4 in the saliva of children and adolescents with OCD, while the opposite seemed to occur in adult OCD patients. Since a previous publication, which analyzed DNA methylation of the SLC6A4 promoter, found similar alterations in the saliva and blood as a consequence of a stress test (Nikolova et al., 2014), we tested whether SLC6A4 DNA methylation levels in pediatric OCD in blood are 
similar to those in saliva. Although both groups (saliva and blood) were age, age of onset and sex matched, we did not find similar methylation levels, which might be due to the fact that the saliva and blood samples were not collected from the same individuals. This is in contrast to the findings of Smith et al. (2015), in which the cg03363743 (within the current MS-HRM analysis) was found to correlate significantly between blood and saliva from the sample participants $(\mathrm{R} 2=0.775, \mathrm{t}=6.5, \mathrm{p}=5.19 \mathrm{E}-8)$. Tissue methylation specificity is supported by the data from the Complex Disease Epigenetics Group, as observed for the CpG site cg03363743, included in our MS-HRM analysis (Suppl. Figure S2), with DNA methylation of around 30\% for prefrontal cortex, entorhinal cortex, superior temporal gyrus, and blood, while low in cerebellum (ca. 15\%) (Extracted from the Complex Disease Epigenetics Group (Hannon et al., 2015), http://epigenetics.iop.kcl.ac.uk/bloodbrain/?probenameg=Cg03363743). However, during brain development, the methylation levels for the CpG site cg03363743 seems to vary between 0.5 to $35 \%$ ((Spiers et al., 2015) http://epigenetics.essex.ac.uk/fetalbrain2/). Such variations were also observed in a recent study measuring SLC6A4 promoter methylation levels in whole blood, saliva and buccal cells with methylation of $0 \%$ up to $14 \%$ (Ismaylova et al., 2017).

We found that age correlated with decreasing SLC6A4 DNA methylation levels (Suppl. Table S4). Moreover, medication, in particular SSRI's, may cause methylation alteration, since the serotonin transporter is the pathogenetic target of the first-line medication used for OCD treatment. For example, lower DNA methylation in the SLC6A4 gene region, responsible for transcriptional control upstream of exon 1A, has been associated with an impaired therapeutic response to the antidepressant citalopram (Domschke et al., 2014). Okada and colleagues (Okada et al., 2014) demonstrated that a treatment with antidepressants of Japanese patients with a major depressive disorder (treated with paroxetine, fluvoxamine, or milnaciprane for 6 weeks) resulted in an increase in DNA methylation levels (in blood) of CpG site 3 of their amplicon in the promoter region of $S L C 6 A 4$, as well as correlating with the 
improvement ratio. Taking age, gender, and medication (SSRIs) as confounders, resulted in a significantly higher methylation level in pediatric OCD compared to matched controls. This, however, was not due to SSRI medication; there was an interaction with age and gender.

Some evidence for cortisol levels and SLC6A4 promoter DNA methylation levels correlation has been reported (Alexander et al., 2014; Ouellet-Morin et al., 2013). In the current study, morning awakening salivary cortisol levels positively correlated with salivary SLC6A4 DNA methylation levels (Suppl. Table S5). Moreover, morning salivary cortisol levels were lower in OCD patients compared to the matched control group (Suppl. Table S1). A lower morning basal salivary cortisol level was observed in healthy children having high daily perceived stress (Maldonado et al., 2008) as well as in, for instance, emergency department nurses reporting higher stress at work compared to general ward nurses (Yang et al., 2001). Perceived stress leading to lower morning salivary levels might be a sign of chronic stress, which is hypothesized to be a risk factor for OCD development (Faravelli et al., 2012; Gothelf et al., 2004; Morgado et al., 2013; Morina et al., 2016).

Lastly, the combination and interaction of genetic and epigenetic effects may play an important role in the risk of vulnerability to psychiatric disorders. Therefore, we determined SLC6A4 DNA methylation levels as a function of the genotypes at the 5-HTTLPR triallelic polymorphism, rs25532 and rs16965628 (Suppl. Results Fig. S3). We did not detect statistically significant differences in DNA methylation levels depending on the investigated genotypes. However, due to the relatively small sample size of our study, such methylation alterations need to be investigated in a larger study group. A previous study also failed to find an association between the 5-HTTLPR triallelic polymorphism and SLC6A4 DNA methylation (Domschke et al., 2014). However, the association between genotype and DNA methylation could be more complex or dependent on the particular promoter region studied (Vijayendran et al., 2012). 
In summary, our pilot study demonstrated an increase in the SLC6A4 promoter DNA methylation levels in the saliva of children and adolescents with OCD. DNA methylation provides one important epigenetic mechanism through which environmental influences can affect psychiatric disease risk. Further replications of these data on independent study cohorts are warranted in order to elucidate the potential role of DNA methylation in OCD.

\section{Acknowledgements}

We credit the excellent technical assistance of Miryame Hofmann and Susanne KunertDümpelmann, Sonja Fetz and Seema Mehta. Furthermore, we wish to credit the student Tejaswini Hardas.

\section{Funding}

Zoya Marinova was supported by a Marie Heim-Vögtlin fellowship from the Swiss National Science Foundation. The work was supported by the Olga Mayenfisch foundation and the Swiss National Science Foundation [grant number SW 320030-130237].

\section{References}

Alexander N, Wankerl M, Hennig J, Miller R, Zankert S, Steudte-Schmiedgen S, Stalder T, \& Kirschbaum C. DNA methylation profiles within the serotonin transporter gene moderate the association of 5-HTTLPR and cortisol stress reactivity. Transl Psychiatry 2014; 4: e443.

American Psychiatric Association. Diagnostic and Statistical Manual of Mental Disorders, Fifth Edition (DSM-5) (5 $5^{\text {th }}$ ed.). Washington DC: APA, 2013.

Atmaca M, Onalan E, Yildirim H, Yuce H, Koc M, Korkmaz S, \& Mermi O. Serotonin transporter gene polymorphism implicates reduced orbito-frontal cortex in obsessive-compulsive disorder. J Anxiety Disord 2011; 25: 680-685.

Baca-Garcia E, Salgado BR, Segal HD, Lorenzo CV, Acosta MN, Romero MA, Hernandez MD, SaizRuiz J, Fernandez Piqueras J, \& de Leon J. A pilot genetic study of the continuum between compulsivity and impulsivity in females: the serotonin transporter promoter polymorphism. Prog Neuropsychopharmacol Biol Psychiatry 2005; 29: 713-717.

Begg CB, \& Mazumdar M. Operating characteristics of a rank correlation test for publication bias. Biometrics 1994; 50: 1088-1101. 
Bengel D, Greenberg BD, Cora-Locatelli G, Altemus M, Heils A, Li Q, \& Murphy DL. Association of the serotonin transporter promoter regulatory region polymorphism and obsessive-compulsive disorder. Mol Psychiatry 1999; 4: 463-466.

Billett EA, Richter MA, King N, Heils A, Lesch KP, \& Kennedy JL. Obsessive compulsive disorder, response to serotonin reuptake inhibitors and the serotonin transporter gene. Mol Psychiatry 1997; 2: 403-406.

Bloch MH, Landeros-Weisenberger A, Sen S, Dombrowski P, Kelmendi B, Coric V, Pittenger C, \& Leckman JF. Association of the serotonin transporter polymorphism and obsessivecompulsive disorder: systematic review. Am J Med Genet B Neuropsychiatr Genet 2008; 147B: 850-858.

Camarena B, Rinetti G, Cruz C, Hernandez S, de la Fuente JR, \& Nicolini H. Association study of the serotonin transporter gene polymorphism in obsessive-compulsive disorder. Int $\mathbf{J}$ Neuropsychopharmacol 2001; 4: 269-272.

Cengiz M, Okutan SN, Bayoglu B, Sakalli Kani A, Bayar R, \& Kocabasoglu N. Genetic Polymorphism of the Serotonin Transporter Gene, SLC6A4 rs16965628, Is Associated with Obsessive Compulsive Disorder. Genet Test Mol Biomarkers 2015; 19: 228-234.

Chabane N, Millet B, Delorme R, Lichtermann D, Mathieu F, Laplanche JL, Roy I, Mouren MC, Hankard R, Maier W, Launay JM, \& Leboyer M. Lack of evidence for association between serotonin transporter gene (5-HTTLPR) and obsessive-compulsive disorder by case control and family association study in humans. Neurosci Lett 2004; 363: 154-156.

Denys D, Van Nieuwerburgh F, Deforce D, \& Westenberg HG. Association between serotonergic candidate genes and specific phenotypes of obsessive compulsive disorder. J Affect Disord 2006; 91: 39-44.

Di Bella D, Erzegovesi S, Cavallini MC, \& Bellodi L. Obsessive-Compulsive Disorder, 5-HTTLPR polymorphism and treatment response. Pharmacogenomics J 2002; 2: 176-181.

Dickel DE, Veenstra-VanderWeele J, Bivens NC, Wu X, Fischer DJ, Van Etten-Lee M, Himle JA, Leventhal BL, Cook EH, Jr., \& Hanna GL. Association studies of serotonin system candidate genes in early-onset obsessive-compulsive disorder. Biol Psychiatry 2007; 61: 322-329.

Domschke K, Tidow N, Schwarte K, Deckert J, Lesch KP, Arolt V, Zwanzger P, \& Baune BT. Serotonin transporter gene hypomethylation predicts impaired antidepressant treatment response. Int J Neuropsychopharmacol 2014; 17: 1167-1176.

Egger M, Davey Smith G, Schneider M, \& Minder C. Bias in meta-analysis detected by a simple, graphical test. BMJ 1997; 315: 629-634.

Faravelli C, Lo Sauro C, Godini L, Lelli L, Benni L, Pietrini F, Lazzeretti L, Talamba GA, Fioravanti G, \& Ricca V. Childhood stressful events, HPA axis and anxiety disorders. World J Psychiatry 2012; $2: 13-25$. 
Frisch A, Michaelovsky E, Rockah R, Amir I, Hermesh H, Laor N, Fuchs C, Zohar J, Lerer B, Buniak SF, Landa S, Poyurovsky M, Shapira B, \& Weizman R. Association between obsessivecompulsive disorder and polymorphisms of genes encoding components of the serotonergic and dopaminergic pathways. Eur Neuropsychopharmacol 2000; 10: 205-209.

Gothelf D, Aharonovsky O, Horesh N, Carty T, \& Apter A. Life events and personality factors in children and adolescents with obsessive-compulsive disorder and other anxiety disorders. Compr Psychiatry 2004; 45: 192-198.

Grados MA, Samuels J, Shugart YY, Willour VL, Wang Y, Cullen B, Bienvenu OJ, Hoehn-Saric R, Valle D, Liang KY, Riddle MA, Wendland JR, Murphy DL, Nestadt G, \& Detera-Wadleigh S. Rare plus common SERT variants in obsessive-compulsive disorder. Mol Psychiatry 2007; 12 : 422-423.

Grünblatt E, Bartl J, Zehetmayer S, Ringel TM, Bauer P, Riederer P, \& Jacob CP. Gene expression as peripheral biomarkers for sporadic Alzheimer's disease. J Alzheimers Dis 2009; 16: 627-634.

Grünblatt E, Schlosser R, Fischer P, Fischer MO, Li J, Koutsilieri E, Wichart I, Sterba N, Rujescu D, Moller HJ, Adamcyk W, Dittrich B, Muller F, Oberegger K, Gatterer G, Jellinger KJ, Mostafaie N, Jungwirth S, Huber K, Tragl KH, Danielczyk W, \& Riederer P. Oxidative stress related markers in the "VITA" and the centenarian projects. Neurobiol Aging 2005; 26: 429438.

Hannon E, Lunnon K, Schalkwyk L, \& Mill J. Interindividual methylomic variation across blood, cortex, and cerebellum: implications for epigenetic studies of neurological and neuropsychiatric phenotypes. Epigenetics 2015; 10: 1024-1032.

Hauser TU, Iannaccone R, Dolan RJ, Ball J, Hattenschwiler J, Drechsler R, Rufer M, Brandeis D, Walitza S, \& Brem S. Increased fronto-striatal reward prediction errors moderate decision making in obsessive-compulsive disorder. Psychol Med 2017; 1-13.

Honda S, Nakao T, Mitsuyasu H, Okada K, Gotoh L, Tomita M, Sanematsu H, Murayama K, Ikari K, Kuwano M, Yoshiura T, Kawasaki H, \& Kanba S. A pilot study exploring the association of morphological changes with 5-HTTLPR polymorphism in OCD patients. Ann Gen Psychiatry 2017; $16: 2$.

Hu XZ, Lipsky RH, Zhu G, Akhtar LA, Taubman J, Greenberg BD, Xu K, Arnold PD, Richter MA, Kennedy JL, Murphy DL, \& Goldman D. Serotonin transporter promoter gain-of-function genotypes are linked to obsessive-compulsive disorder. Am J Hum Genet 2006; 78: 815-826.

Ismaylova E, Di Sante J, Szyf M, Nemoda Z, Yu WJ, Pomares FB, Turecki G, Gobbi G, Vitaro F, Tremblay RE, \& Booij L. Serotonin transporter gene promoter methylation in peripheral cells in healthy adults: Neural correlates and tissue specificity. Eur Neuropsychopharmacol 2017; 27: 1032-1041.

Jaenisch R, \& Bird A. Epigenetic regulation of gene expression: how the genome integrates intrinsic and environmental signals. Nat Genet 2003; 33 Suppl: 245-254. 
Kenezloi E, Lakatos K, Gadoros J, Meszaros G, Sasvari-Szekely M, \& Nemoda Z. Factor Analysis of Childhood Onset Obsessive-Compulsive Disorder: Symptom Dimensions and Association Analysis with the Serotonin Transporter Gene, 19th World Congress of the International Association for Child and Adolescent Psychiatry and Allied Professions (IACAPAP) 2010;(p. 50). Beijing, China: Chinese Medical Journal.

Kim SJ, Lee HS, \& Kim CH. Obsessive-compulsive disorder, factor-analyzed symptom dimensions and serotonin transporter polymorphism. Neuropsychobiology 2005; 52: 176-182.

Kinnear CJ, Niehaus DJ, Moolman-Smook JC, du Toit PL, van Kradenberg J, Weyers JB, Potgieter A, Marais V, Emsley RA, Knowles JA, Corfield VA, Brink PA, \& Stein DJ. Obsessivecompulsive disorder and the promoter region polymorphism (5-HTTLPR) in the serotonin transporter gene (SLC6A4): a negative association study in the Afrikaner population. Int $\mathbf{J}$ Neuropsychopharmacol 2000; 3: 327-331.

Lin PY. Meta-analysis of the association of serotonin transporter gene polymorphism with obsessivecompulsive disorder. Prog Neuropsychopharmacol Biol Psychiatry 2007; 31: 683-689.

Liu SG, Zhang XH, Yin YY, Wang MJ, Che FY, \& Ma X. An association analysis between 5HTTLPR polymorphism and obsessive-compulsive disorder, Tourette syndrome in a Chinese Han population. CNS Neurosci Ther 2011; 17: 793-795.

Mak L, Streiner DL, \& Steiner M. Is serotonin transporter polymorphism (5-HTTLPR) allele status a predictor for obsessive-compulsive disorder? A meta-analysis. Arch Womens Ment Health 2015; 18: 435-445.

Maldonado EF, Fernandez FJ, Trianes MV, Wesnes K, Petrini O, Zangara A, Enguix A, \& Ambrosetti L. Cognitive performance and morning levels of salivary cortisol and alpha-amylase in children reporting high vs. low daily stress perception. Span J Psychol 2008; 11: 3-15.

Martin J, Cleak J, Willis-Owen SA, Flint J, \& Shifman S. Mapping regulatory variants for the serotonin transporter gene based on allelic expression imbalance. Mol Psychiatry 2007; 12: 421-422.

Mataix-Cols D, Boman M, Monzani B, Ruck C, Serlachius E, Langstrom N, \& Lichtenstein P. Population-based, multigenerational family clustering study of obsessive-compulsive disorder. JAMA Psychiatry 2013; 70: 709-717.

Mattheisen M, Samuels JF, Wang Y, Greenberg BD, Fyer AJ, McCracken JT, Geller DA, Murphy DL, Knowles JA, Grados MA, Riddle MA, Rasmussen SA, McLaughlin NC, Nurmi EL, Askland KD, Qin HD, Cullen BA, Piacentini J, Pauls DL, Bienvenu OJ, Stewart SE, Liang KY, Goes FS, Maher B, Pulver AE, Shugart YY, Valle D, Lange C, \& Nestadt G. Genomewide association study in obsessive-compulsive disorder: results from the OCGAS. Mol Psychiatry 2014; 
Mattina GF, \& Steiner M. The need for inclusion of sex and age of onset variables in genetic association studies of obsessive-compulsive disorder: Overview. Prog Neuropsychopharmacol Biol Psychiatry 2016; 67: 107-116.

McDougle CJ, Epperson CN, Price LH, \& Gelernter J. Evidence for linkage disequilibrium between serotonin transporter protein gene (SLC6A4) and obsessive compulsive disorder. Mol Psychiatry 1998; 3: 270-273.

Meira-Lima I, Shavitt RG, Miguita K, Ikenaga E, Miguel EC, \& Vallada H. Association analysis of the catechol-o-methyltransferase (COMT), serotonin transporter (5-HTT) and serotonin 2A receptor (5HT2A) gene polymorphisms with obsessive-compulsive disorder. Genes Brain Behav 2004; 3: 75-79.

Migheli F, Stoccoro A, Coppede F, Wan Omar WA, Failli A, Consolini R, Seccia M, Spisni R, Miccoli P, Mathers JC, \& Migliore L. Comparison study of MS-HRM and pyrosequencing techniques for quantification of APC and CDKN2A gene methylation. PLoS One 2013; 8: e52501.

Moher D, Liberati A, Tetzlaff J, Altman DG, \& Group P. Preferred reporting items for systematic reviews and meta-analyses: the PRISMA statement. BMJ 2009; 339: b2535.

Morgado P, Freitas D, Bessa JM, Sousa N, \& Cerqueira JJ. Perceived Stress in Obsessive-Compulsive Disorder is Related with Obsessive but Not Compulsive Symptoms. Front Psychiatry 2013; 4: 21.

Morina N, Sulaj V, Schnyder U, Klaghofer R, Muller J, Martin-Solch C, \& Rufer M. Obsessivecompulsive and posttraumatic stress symptoms among civilian survivors of war. BMC Psychiatry 2016; 16: 115.

Moya PR, Wendland JR, Rubenstein LM, Timpano KR, Heiman GA, Tischfield JA, King RA, Andrews AM, Ramamoorthy S, McMahon FJ, \& Murphy DL. Common and rare alleles of the serotonin transporter gene, SLC6A4, associated with Tourette's disorder. Mov Disord 2013; 28: $1263-1270$.

Murphy DL, Moya PR, Fox MA, Rubenstein LM, Wendland JR, \& Timpano KR. Anxiety and affective disorder comorbidity related to serotonin and other neurotransmitter systems: obsessive-compulsive disorder as an example of overlapping clinical and genetic heterogeneity. Philos Trans R Soc Lond B Biol Sci 2013; 368: 20120435.

Nikolova YS, Koenen KC, Galea S, Wang CM, Seney ML, Sibille E, Williamson DE, \& Hariri AR. Beyond genotype: serotonin transporter epigenetic modification predicts human brain function. Nat Neurosci 2014; 17: 1153-1155.

Nissen JB, Hansen CS, Starnawska A, Mattheisen M, Borglum AD, Buttenschon HN, \& Hollegaard M. DNA Methylation at the Neonatal State and at the Time of Diagnosis: Preliminary Support for an Association with the Estrogen Receptor 1, Gamma-Aminobutyric Acid B Receptor 1, 
and Myelin Oligodendrocyte Glycoprotein in Female Adolescent Patients with OCD. Front Psychiatry 2016; 7: 35.

Nyffeler J, Walitza S, Bobrowski E, Gundelfinger R, \& Grunblatt E. Association study in siblings and case-controls of serotonin- and oxytocin-related genes with high functioning autism. J Mol Psychiatry 2014; $2: 1$.

Okada S, Morinobu S, Fuchikami M, Segawa M, Yokomaku K, Kataoka T, Okamoto Y, Yamawaki S, Inoue T, Kusumi I, Koyama T, Tsuchiyama K, Terao T, Kokubo Y, \& Mimura M. The potential of SLC6A4 gene methylation analysis for the diagnosis and treatment of major depression. J Psychiatr Res 2014; 53: 47-53.

Ouellet-Morin I, Wong CC, Danese A, Pariante CM, Papadopoulos AS, Mill J, \& Arseneault L. Increased serotonin transporter gene (SERT) DNA methylation is associated with bullying victimization and blunted cortisol response to stress in childhood: a longitudinal study of discordant monozygotic twins. Psychol Med 2013; 43: 1813-1823.

Pauls DL, Abramovitch A, Rauch SL, \& Geller DA. Obsessive-compulsive disorder: an integrative genetic and neurobiological perspective. Nat Rev Neurosci 2014; 15: 410-424.

Provenzi L, Giorda R, Beri S, \& Montirosso R. SLC6A4 methylation as an epigenetic marker of life adversity exposures in humans: A systematic review of literature. Neurosci Biobehav Rev 2016; 71: 7-20.

Purcell S, Neale B, Todd-Brown K, Thomas L, Ferreira MA, Bender D, Maller J, Sklar P, de Bakker PI, Daly MJ, \& Sham PC. PLINK: a tool set for whole-genome association and populationbased linkage analyses. Am J Hum Genet 2007; 81: 559-575.

Rocha FF, Marco LA, Romano-Silva MA, \& Correa H. Obsessive-compulsive disorder and 5HTTLPR. Rev Bras Psiquiatr 2009; 31: 287-288.

Ruscio AM, Stein DJ, Chiu WT, \& Kessler RC. The epidemiology of obsessive-compulsive disorder in the National Comorbidity Survey Replication. Mol Psychiatry 2010; 15: 53-63.

Saiz PA, Garcia-Portilla MP, Arango C, Morales B, Bascaran MT, Martinez-Barrondo S, Florez G, Sotomayor E, Paredes B, Alvarez C, San Narciso G, Carreno E, Bombin I, Alvarez V, Coto E, Fernandez JM, Bousono M, \& Bobes J. Association study between obsessive-compulsive disorder and serotonergic candidate genes. Prog Neuropsychopharmacol Biol Psychiatry 2008; 32: 765-770.

Smith AK, Kilaru V, Klengel T, Mercer KB, Bradley B, Conneely KN, Ressler KJ, \& Binder EB. DNA extracted from saliva for methylation studies of psychiatric traits: evidence tissue specificity and relatedness to brain. Am J Med Genet B Neuropsychiatr Genet 2015; 168B: $36-44$.

Spiers H, Hannon E, Schalkwyk LC, Smith R, Wong CC, O'Donovan MC, Bray NJ, \& Mill J. Methylomic trajectories across human fetal brain development. Genome Res 2015; 25: 338352. 
Stewart SE, Yu D, Scharf JM, Neale BM, Fagerness JA, Mathews CA, Arnold PD, Evans PD, Gamazon ER, Davis LK, Osiecki L, McGrath L, Haddad S, Crane J, Hezel D, Illman C, Mayerfeld C, Konkashbaev A, Liu C, Pluzhnikov A, Tikhomirov A, Edlund CK, Rauch SL, Moessner R, Falkai P, Maier W, Ruhrmann S, Grabe HJ, Lennertz L, Wagner M, Bellodi L, Cavallini MC, Richter MA, Cook EH, Jr., Kennedy JL, Rosenberg D, Stein DJ, Hemmings SM, Lochner C, Azzam A, Chavira DA, Fournier E, Garrido H, Sheppard B, Umana P, Murphy DL, Wendland JR, Veenstra-VanderWeele J, Denys D, Blom R, Deforce D, Van Nieuwerburgh F, Westenberg HG, Walitza S, Egberts K, Renner T, Miguel EC, Cappi C, Hounie AG, Conceicao do Rosario M, Sampaio AS, Vallada H, Nicolini H, Lanzagorta N, Camarena B, Delorme R, Leboyer M, Pato CN, Pato MT, Voyiaziakis E, Heutink P, Cath DC, Posthuma D, Smit JH, Samuels J, Bienvenu OJ, Cullen B, Fyer AJ, Grados MA, Greenberg BD, McCracken JT, Riddle MA, Wang Y, Coric V, Leckman JF, Bloch M, Pittenger C, Eapen V, Black DW, Ophoff RA, Strengman E, Cusi D, Turiel M, Frau F, Macciardi F, Gibbs JR, Cookson MR, Singleton A, North American Brain Expression C, Hardy J, et al. Genome-wide association study of obsessive-compulsive disorder. Mol Psychiatry 2013; 18: 788-798.

Sugawara H, Bundo M, Ishigooka J, Iwamoto K, \& Kato T. Epigenetic regulation of serotonin transporter in psychiatric disorders. J Genet Genomics 2013; 40: 325-329.

Taylor S. Molecular genetics of obsessive-compulsive disorder: a comprehensive meta-analysis of genetic association studies. Mol Psychiatry 2013; 18: 799-805.

Taylor S. Disorder-specific genetic factors in obsessive-compulsive disorder: A comprehensive metaanalysis. Am J Med Genet B Neuropsychiatr Genet 2016; 171B: 325-332.

Tibrewal P, Kumar HB, Shubha GN, Subhashree D, Purushottam M, Thennarasu K, Reddy YC, \& Jain S. Association of serotonin transporter gene polymorphisms with obsessive-compulsive disorder (OCD) in a south Indian population. Indian J Med Res 2010; 132: 690-695.

Tükel R, Alkas E, Gurvit H, Aslantas Ertekin B, Ertekin E, Baran B, Akca Kalem S, \& Saruhan Direskeneli G. Serotonin transporter promoter polymorphism is associated with executive function impairments in patients with obsessive compulsive disorder. Clin Neuropsychol 2016; 30: 536-546.

van Grootheest DS, Cath DC, Beekman AT, \& Boomsma DI. Twin studies on obsessive-compulsive disorder: a review. Twin Res Hum Genet 2005; 8: 450-458.

Vandesompele J, De Preter K, Pattyn F, Poppe B, Van Roy N, De Paepe A, \& Speleman F. Accurate normalization of real-time quantitative RT-PCR data by geometric averaging of multiple internal control genes. Genome Biol 2002; 3: RESEARCH0034.

Vijayendran M, Beach SR, Plume JM, Brody GH, \& Philibert RA. Effects of genotype and child abuse on DNA methylation and gene expression at the serotonin transporter. Front Psychiatry 2012; 3: 55. 
Voyiaziakis E, Evgrafov O, Li D, Yoon HJ, Tabares P, Samuels J, Wang Y, Riddle MA, Grados MA, Bienvenu OJ, Shugart YY, Liang KY, Greenberg BD, Rasmussen SA, Murphy DL, Wendland JR, McCracken JT, Piacentini J, Rauch SL, Pauls DL, Nestadt G, Fyer AJ, \& Knowles JA. Association of SLC6A4 variants with obsessive-compulsive disorder in a large multicenter US family study. Mol Psychiatry 2011; 16: 108-120.

Walitza S, Marinova Z, Grünblatt E, Lazic SE, Remschmidt H, Vloet TD, \& Wendland JR. Trio study and meta-analysis support the association of genetic variation at the serotonin transporter with early-onset obsessive-compulsive disorder. Neurosci Lett 2014; 580: 100-103.

Walitza S, Wewetzer C, Gerlach M, Klampfl K, Geller F, Barth N, Hahn F, Herpertz-Dahlmann B, Gossler M, Fleischhaker C, Schulz E, Hebebrand J, Warnke A, \& Hinney A. Transmission disequilibrium studies in children and adolescents with obsessive-compulsive disorders pertaining to polymorphisms of genes of the serotonergic pathway. J Neural Transm 2004; 111: $817-825$.

Wendland JR, Kruse MR, Cromer KR, \& Murphy DL. A large case-control study of common functional SLC6A4 and BDNF variants in obsessive-compulsive disorder. Neuropsychopharmacology 2007; 32: 2543-2551.

Wendland JR, Martin BJ, Kruse MR, Lesch KP, \& Murphy DL. Simultaneous genotyping of four functional loci of human SLC6A4, with a reappraisal of 5-HTTLPR and rs25531. Mol Psychiatry 2006; 11: 224-226.

Wendland JR, Moya PR, Kruse MR, Ren-Patterson RF, Jensen CL, Timpano KR, \& Murphy DL. A novel, putative gain-of-function haplotype at SLC6A4 associates with obsessive-compulsive disorder. Hum Mol Genet 2008; 17: 717-723.

Wittchen HU, Jacobi F, Rehm J, Gustavsson A, Svensson M, Jonsson B, Olesen J, Allgulander C, Alonso J, Faravelli C, Fratiglioni L, Jennum P, Lieb R, Maercker A, van Os J, Preisig M, Salvador-Carulla L, Simon R, \& Steinhausen HC. The size and burden of mental disorders and other disorders of the brain in Europe 2010. Eur Neuropsychopharmacol 2011; 21: 655679.

Yang Y, Koh D, Ng V, Lee FC, Chan G, Dong F, \& Chia SE. Salivary cortisol levels and work-related stress among emergency department nurses. J Occup Environ Med 2001; 43: 1011-1018.

Yue W, Cheng W, Liu Z, Tang Y, Lu T, Zhang D, Tang M, \& Huang Y. Genome-wide DNA methylation analysis in obsessive-compulsive disorder patients. Sci Rep 2016; 6: 31333. 


\section{Figure Legends}

Figure 1. Summary and meta-analysis of all published association analyses of the serotonin transporter 5-HTTLPR+rs25531, rs16965628 and rs25532 with obsessive-compulsive disorder (OCD). (A) forest plot for 5-HTTLPR+rs25531 gain-of-function $\mathrm{L}_{\mathrm{A}}$ allele versus $\mathrm{L}_{\mathrm{G}}+\mathrm{S}$ allele in OCD. (B) forest plot for 5-HTTLPR+rs25531 gain-of-function $\mathrm{L}_{\mathrm{A}}$ allele versus $\mathrm{L}_{\mathrm{G}}+\mathrm{S}$ allele in early-onset pediatric OCD. (C) forest plot for rs16965628 C allele versus $\mathrm{G}$ allele in OCD. (D) forest plot for rs25532 $\mathrm{T}$ allele versus $\mathrm{C}$ allele in OCD. Black whiskers in the forest plot represent $95 \%$ confidence intervals (CI) for odds ratio; the sample size is reflected in symbol size. Sample demographics and study quality was summarized in Suppl. Table S2. Abbreviations: CC, case-control; TDT, transmission disequilibrium test; FBAT, family-based association testing.

Figure 2. SLC6A4 DNA methylation in saliva and gene expression in whole blood of earlyonset pediatric obsessive-compulsive disorder (OCD) patients, pediatric healthy controls, adult OCD and adult healthy controls. A. DNA methylation levels in saliva, presented as mean \pm SEM. B. Gene expression levels in whole blood RNA samples, presented as mean \pm SEM. Normalization of SLC6A4 mRNA was conducted using qBasePLUS v.2.3 with the four reference genes: $A C T B, G A P D H, A L A S 1$ and RPL13A. Kruskal-Wallis test followed by Mann-Whitney Test * $\mathrm{p}<0.05$ vs. saliva pediatric control; ** $\mathrm{p}<0.05$ vs. saliva pediatric OCD; $+\mathrm{p}<0.05$ vs. saliva adult control 


\section{ACCEPTED MANUSCRIPT}

Table 1. Demographic characteristics for the pediatric OCD and control subjects used for the case-control and the pediatric OCD patients of the family-trio study.

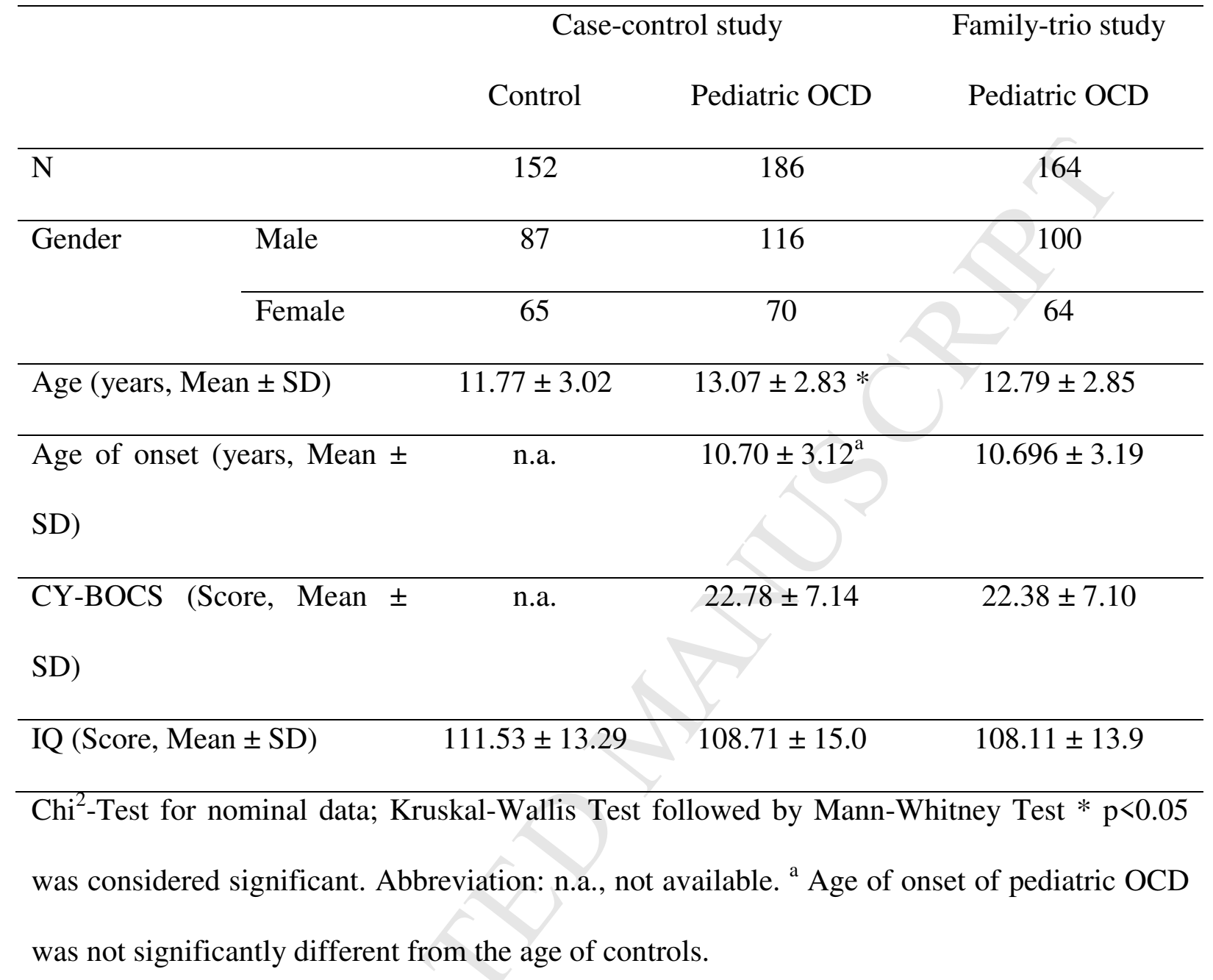




\section{ACCEPTED MANUSCRIPT}

Table 2. Case-control association analysis of SLC6A4 promoter polymorphism in pediatric OCD.

\begin{tabular}{|c|c|c|c|c|c|c|c|c|c|c|c|}
\hline CHR & SNP & $\overline{\mathrm{BP}}$ & A1 & F_A & $\bar{F}+U$ & $\mathrm{~A} 2$ & $\mathrm{P}$ & OR & SE & L95 & U95 \\
\hline 17 & rs16965628 & 30228407 & $\mathrm{C}$ & 0.06216 & 0.07432 & $\bar{G}$ & 0.5388 & 0.8255 & 0.309 & 0.4505 & 1.513 \\
\hline 17 & rs25532 & 30237152 & $\mathrm{~T}$ & 0.1189 & 0.1689 & $\mathrm{C}$ & 0.0733 & 0.664 & 0.2233 & 0.4287 & 1.029 \\
\hline 17 & HTTLPR+rs25531 & 30237328 & $\mathrm{~S}+\mathrm{L}$ & 0.4375 & 0.4671 & $\overline{\mathrm{L}_{\mathrm{A}}}$ & 0.4834 & 0.8873 & 0.1557 & 0.6539 & 1.204 \\
\hline
\end{tabular}

Fisher's exact test (allelic association).

Abbreviations, BP, physical position (base-pair); A1, minor allele name; F_A, Frequency of minor allele in cases; F_U, frequency of minor allele in controls; A2, major allele name; Pexact p-value for this test; OR, estimated odds ratio (for A1); SE, standard error; L95, lower bound of $95 \%$ confidence interval for odds ratio; U95, upper bound of $95 \%$ confidence interval for odds ratio 
Table 3. Transmission disequilibrium test for association of SLC6A4 promoter polymorphism in pediatric OCD

\begin{tabular}{|c|c|c|c|c|c|c|c|c|c|c|c|c|c|c|c|c|c|c|}
\hline CHR & SNP & $\mathrm{BP}$ & $\mathrm{A} 1: \mathrm{A} 2$ & $\mathrm{~T}$ & $\mathrm{U}$ & OR & L95 & U95 & CHISQ & $\mathrm{P}$ & T:U_PAT & CHISQ_PAT & P_PAT & T:U_MAT & CHISQ_MAT & P_MAT & Z_POO & P_POO \\
\hline 17 & rs16965628 & 30228407 & C:G & 15 & 21 & 0.7143 & 0.3682 & 1.386 & 1 & 0.3173 & 07:10 & 0.5294 & 0.4669 & 08:11 & 0.4737 & 0.4913 & -0.05643 & 0.955 \\
\hline 17 & rs 25532 & 30237152 & $\mathrm{~T}: \mathrm{C}$ & 24 & 37 & 0.6486 & 0.3881 & 1.084 & 2.77 & 0.09602 & $12: 24$ & 4 & 0.0455 & $12: 13$ & 0.04 & 0.8415 & -1.148 & 0.251 \\
\hline 17 & HTTLPR+rs25531 & 30237328 & $\mathrm{~S}+\mathrm{L}_{\mathrm{G}}: \mathrm{L}$ & 55 & 73 & 0.7534 & 0.531 & 1.069 & 2.531 & 0.1116 & 35.5 & 1.63 & .2004 & 37.5 & 0.9552 & 0.3284 & .2541 & 0.79 \\
\hline
\end{tabular}

Abbreviations: BP, physical position (base-pair); A1, minor allele name; A2, major allele name; T, transmitted minor allele count, U, untransmitted allele count; OR, TDT odds ratio; L95, lower bound of 95\% confidence interval for odds ratio; U95, upper bound of 95\% confidence interval for odds ratio; CHISQ, TDT chi-square statistic; P, TDT asymptotic p-value; T:U_PAT, Paternal transmitted : untransmitted counts; CHISQ_PAT, paternal chi-squared test; P_PAT, paternal asymptotic p-value; T:U_MAT, maternal transmitted : untransmitted counts; CHISQ_MAT, maternal chi-squared test; P_MAT, maternal asymptotic p-value; Z_POO, Z score for difference in paternal versus maternal odds ratios; P_POO, asymptotic p-value for paternal-of origin test; Bold, Nominal significance $\mathrm{p}<0.05$. 


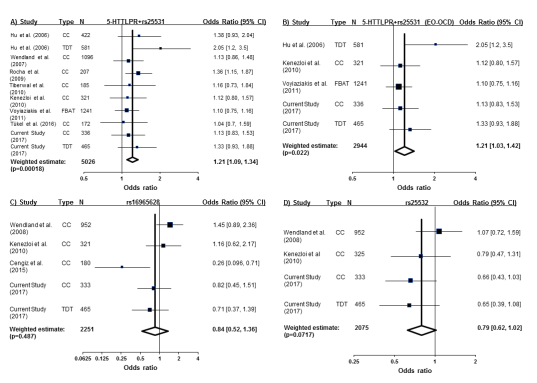




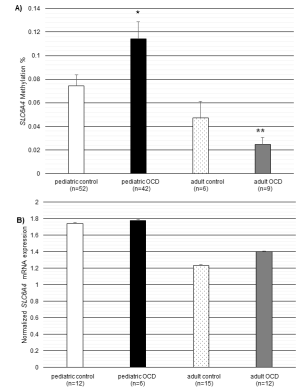




\section{Ethical Statement}

\section{Human and animal rights}

Participants were recruited at the Departments of Child and Adolescent Psychiatry of the Universities of Würzburg, Zurich ( $\mathrm{n}=145$ cases from Würzburg \& Zurich), Marburg, Aachen and Freiburg. Informed written consent was obtained in all cases by the participants or their parents. The study was approved by the ethical commissions of all involved universities in accordance with the latest version of the Declaration of Helsinki, including an ethical permission granted by the Ethic Committees from Aachen, Würzburg, Marburg, Freiburg and the Cantonal Ethic Commission of Zürich (Ref. Nr. 39/97, 140/3 and EK: KEK-ZH-Nr. 2010-0340/3).

\section{Conflict of Interest}

The authors declare no conflict of interest. Prof. Walitza's disclosure of outside professional activities and interests list: https://www.uzh.ch/prof/ssl-dir/interessenbindungen/client/web/W

\section{Submission declaration and verification}

This manuscript describes original work, has not been previously published and has not been submitted for publication elsewhere while under consideration.

\section{Contributors}

All listed authors approved the manuscript and this submission and agree to be accountable for all aspects of the work.

Edna Grünblatt and Zoya Marinova contributed substantially to the conception, design, acquisition, analysis and interpretation of the work. Both drafted and revised the work. 
Alexander Roth contributed to statistical analysis and interpretation of the work and revising the work critically.

Elena Gardini, Juliane Ball, Julia Geissler and Marcel Romanos contributed to acquisition and analysis of the work and revising the work critically.

Tomasz K Wojdacz contributed to the design and interpretation of the work and revised the work critically.

Susanne Walitza contributed substantially to the conception, design, and interpretation of the work and revised the work critically.

\section{Funding sources}

Zoya Marinova was supported by a Marie Heim-Vögtlin fellowship from the Swiss National Science Foundation. The work was supported by the Olga Mayenfisch foundation and the Swiss National Science Foundation [grant number SW 320030-130237]. 